\title{
Influence of Surface Integrity after Turning on the Consecutive Plasma Nitridation and Bark- hausen Noise Emission
}

\author{
Anna Mičietová ${ }^{1}$, Juraj Uríček ${ }^{1}$, Daniel Heim²${ }^{2}$, Mária Čilliková ${ }^{1}$, Miroslav Neslušan $^{1}$, \\ ${ }^{1}$ Faculty of Mechanical Engineering, University of Žilina, Univerzitná 1, 01026 Žilina, Slovakia, E-mail: anna.micie- \\ tova@fstroj.uniza.sk, mirolav.neslusan@fstroj.uniza.sk, maria.cillikova@fstroj.uniza.sk \\ ${ }^{2}$ Upper Austria University of Applied Sciences, A-4600 Wels, Stelzhamerstraße 23, Austria.
}

This paper deals with non destructive evaluation of components after plasma nitridation via Barkhausen noise techniques. The effect of the different surface state before plasma nitriding is studied via non destructive Barkhausen noise technique as well as the conventional destructive techniques. Turning operation was performed by the use of the inserts of variable flank wear. The results of experiments show that Barkhausen noise emission is a function of tool flank as well as the different regime of heat treatment. The different state of the surface before plasma nitriding results into the different thickness of compound layer. Furthermore, also the underlying diffusion layer state differs.

Keywords: tool wear, plasma nitridation, Barkhausen noise

\section{Introduction}

Nitriding is the outstanding concept in which hard surface is mixed with tough core. Nitriding thermo chemical process is usually conducted to improve fatigue life, wear or corrosion resistance of the components surface [1 - 4]. High hardness of nitrided layers originates from hard nitride micro precipitates due to low solubility of nitrogen in $\alpha$-iron. Nitrogen is produced by the decomposition of ammonia $\mathrm{NH}_{3}$ atmosphere and diffusion layer (as the main nitriding region) is coated by the adjoining compound layer. Diffusion layer usually contains small volume of nitrogen dissolved in $\alpha$-iron together with facecentered cubic $\gamma^{\prime}$-nitride $\mathrm{Fe}_{4} \mathrm{~N}$ and hexahedral $\varepsilon$-nitride $\mathrm{Fe}_{2-3} \mathrm{~N}$ (sometimes orthorhombic $\zeta$-nitride $\mathrm{Fe}_{2} \mathrm{~N}$ ) [2]. On the other hand, compound layer is entirely composed of $\varepsilon$ and $\gamma^{\prime}$ nitrides its thickness is much less compared to diffusion one. Nitriding is widely used in the automotive industry, in the forging industry for the enhancement of forge dies, and in the die-casting industry. As opposed to the carburizing, nitriding requires the lowest temperatures (up to $550^{\circ} \mathrm{C}$ ) of all thermo chemical diffusion techniques [2]. This means that steel does not undergo any phase changes. Moreover, high hardness of nitrided layers is initiated directly during diffusion process whereas case carburized components require subsequent heat treatment. On the other hand, nitriding cannot be completed in the cycle time of carburizing process. Nitriding process can be carried out in a variety of manners. Except gaseous, salt bath or fluidized bed also plasma nitriding is widely used in many real industrial applications. The physical principle of this procedure is based on the glow discharge plasma assisted decomposition of $\mathrm{N}_{2}$. The surface is heated by bombardment with highly energetic positive ions in the plasma.

As opposed to the conventional gas nitriding, plasma nitriding produced compound layer free of porous, better dimensional accuracy of components, higher ductility of nitrided layers, better mechanical properties, surface free annealing and remarkable reduction in nitriding time. $\mathrm{Nu}-$ merous investigations focused on plasma nitriding procedure have been conducted using various nitriding regimes as well as materials. Marot at al. [5] found that improved nitrogen transport can be obtained after nitridation in $\mathrm{NH}_{3}$ plasma without cathodic bias on the samples. Such cold conditions allow the iron matrix to be nitrided in a depth range of $100-400 \mu \mathrm{m}$ at a temperature as low as $350^{\circ} \mathrm{C}$.

The main disadvantage of plasma nitriding can be viewed in more complex process control due to many parameters affecting metallurgy of nitrided components such as nitriding time, temperature of the workpiece and chamber, process gas, work and support fixturing area, power voltage, current density, vacuum level, pulses duration, etc. For this reason, plasma nitriding process needs quite sophisticated process control as well as post processing validation in which plasma nitridation parameters are correlated with surface state of components expressed in such terms as thickness of diffusion and compound layers, their chemistry, hardness profile, surface defects, etc. For instance, Flori at al. [6] analyzed an industrial plasma-nitrided sample which was detected having two types of defects: an external defective layer covering almost all the surface of the nitrided case and a structure with segregations bands. The authors analyzed the samples after plasma nitriding by means X-ray photoelectron spectroscopy, electron probe microanalysis, light microscopy and microhardness measurements for a better understanding of phenomena taking place at the industrial plasma nitriding of steels as well as more accurate valuation of the technological parameters of this thermo chemical treatment. Post processing validation is usually executed via long term and high costs destructive tests such as metallographic observations, micro indentation, and application of SEM, XRD or other techniques. Being so, any reliable non destructive concept developed for such purpose would be beneficial.

One of the possible aspects of plasma nitriding process is preparation of the surface prior plasma nitriding. Expressed in other words, samples history - especially surface state could vary due to micro and macro geometry as well as surface hardening, intensity of mechanical and 
thermal load, corresponding dislocation density, density of crystalline lattice defects or microstructure. Industrial experience indicates that for instance components produced by turning cycles before plasma nitriding could be different considering their surface due to variable tool wear. Especially components turned with tools of highly developed flank wear $V B$ could be found as unacceptable after plasma nitriding process despite keeping correct nitriding and other conditions. Post processing validation is usually executed via long term and high costs destructive tests such as metallographic observations, micro indentation, and application of SEM, XRD or other techniques. Being so, any reliable non destructive concept developed for such purpose would be beneficial.

It is well known that Bloch Walls (BWs) in ferromagnetic bodies during their motion interfere with all crystalline defects such as grain boundaries, dislocation cell, precipitates as well as other non ferromagnetic phases [7 - 12]. Compound layer entirely composed of nitrides should be considered as the non ferromagnetic region progressively decreasing magnetic Barkhausen noise (BN) received on the free surface along with gradual increase in its thickness. Moreover, fine nitrides embedded within the diffusion layer strongly pin BWs thus contribute to the lower BN emission [13]. Being so, BN technique would be promising method for non destructive post processing monitoring of nitriding (focused on plasma nitriding in this study). BN originate from irreversible and discontinuous $\mathrm{BWs}$ motion and $\mathrm{BN}$ emission is strongly related to microstructure state as well as stress state. Plasma nitriding process remarkable alters microstructure in the diffusion layer since establishes very fine nitrides hindering BWs motion. Thus the different density of nitrides would affect $\mathrm{BN}$ emission.

A concept in which components after plasma nitriding process could be monitored via $\mathrm{BN}$ should be based on contrast between high $\mathrm{BN}$ emission associated with reduced nitrides density a vice versa. This paper discusses potential of $\mathrm{BN}$ technique for monitoring components in automotive industry with the focus on influence of components history - influence of previous turning cycles, especially tool wear on the consecutive plasma nitriding process.

\section{Conditions of experiments}

BN measurement was performed by the use of Rollscan 350 device and software package $\mu$ Scan in the frequency range of 70 to $200 \mathrm{kHz}$ (magnetizing frequency $125 \mathrm{~Hz}$, magnetizing voltage $10 \mathrm{~V})$. Magnetic measurements were carried out as the dynamic in the tangential direction (direction of cutting speed). BN signal was recorded during rotation of the sample - motion speed 15 $\mathrm{mm} . \mathrm{s}^{-1}$.

Vickers microhardness readings were conducted by Härteprüfgerät EMCO N3D micro-hardness tester by applying force $500 \mathrm{~g}$ for 10 seconds. Microhardness was determined by averaging 3 repetitive measurements $(3 \mathrm{mi}$ crohardness profiles spaced $0.1 \mathrm{~mm}$ ). To reveal the microstructure transformation induced by nitriding process $20 \mathrm{~mm}$ long pieces were routinely prepared for metallographic observations (hot moulded, ground, polished and etched by $3 \%$ Nital for 10 seconds).

4 series of samples were produced made of steel 14220 in the form of disk (diameter $145 \mathrm{~mm}$ ). Face turning was employed for turning each series containing 5 samples turned with the insert of the different tool wear $V B=0.05$ až $0.95 \mathrm{~mm}(0.05 \mathrm{~mm}, 0.25 \mathrm{~mm}, 0.47 \mathrm{~mm}, 0.60$ $\mathrm{mm}$ and $0.95 \mathrm{~mm}$ ). First series was only turned; the second one was annealed in the furnace at temperature $650^{\circ}$ $\mathrm{C}$ for 2 hours. The third series was annealed after turning and plasma nitrided afterward. The last series was only plasma nitrided after turning. Cutting conditions: cutting speed at the distance approx. $10 \mathrm{~mm}$ from the disk periphery $300 \mathrm{~m} . \mathrm{min}^{-1}, a_{p}=1 \mathrm{~mm}, f=0.102 \mathrm{~mm}$. Plasma nitriding process was performed at temperature $485^{\circ} \mathrm{C}$ for 8 hours.

\section{Results of experiments}

Figs. $1 \div 5$ illustrate that increasing $V B$ strongly affect increasing thickness of the near surface remarkably altered by cutting process. Čížek [4] reported about increasing dislocation density and the corresponding micro hardness along with more developed $V B$ together with the dynamic re-crystallization for surface turned by the use of inserts of $V B=0.6$ a $0.95 \mathrm{~mm}$. Tool properties remarkable contribute to the cutting process [14].

Increasing dislocation density and the transformation processes affect the consecutive plasma nitriding process in two contradictory effects. First one, it enhances nitrides to be embedded in the matrix since dislocation cells are clustered by vacancies as preferential sites for nitrides. The second effect hinders embedding nitrides in the matrix as soon as the density of lattice defects exceeds the critical threshold.

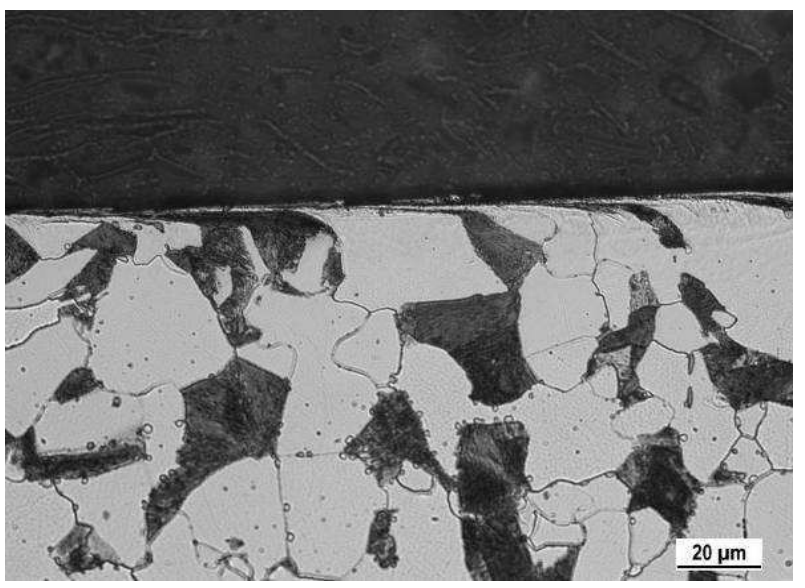

Fig. 1 Metallographic observation of turned surface, VB $=0.05 \mathrm{~mm}$

Dynamic records of BN (see Fig. 6 $\div 10$ ) illustrate that the hindering effect dominates for the surfaces produced with the inserts of higher $V B$. BN values obtained for low $V B=0.05 \mathrm{~mm}$ are lower for only nitrided surface, balanced for $V B=0.25 \mathrm{~mm}$ and higher for $V B=0.47 ; 0.60$ and $0.95 \mathrm{~mm}$ that those for annealed and nitrided. This evolution demonstrates that the positive effect of samples annealing can be found only for samples with more intensive thermal and superimposing mechanical load during turning. 


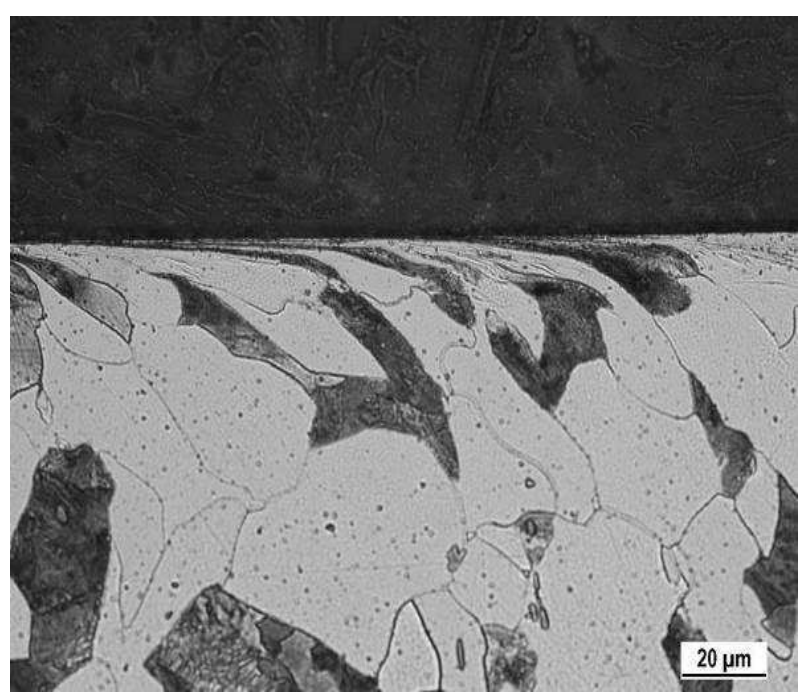

Fig. 2 Metallographic observation of turned surface, VB

$$
=0.25 \mathrm{~mm}
$$

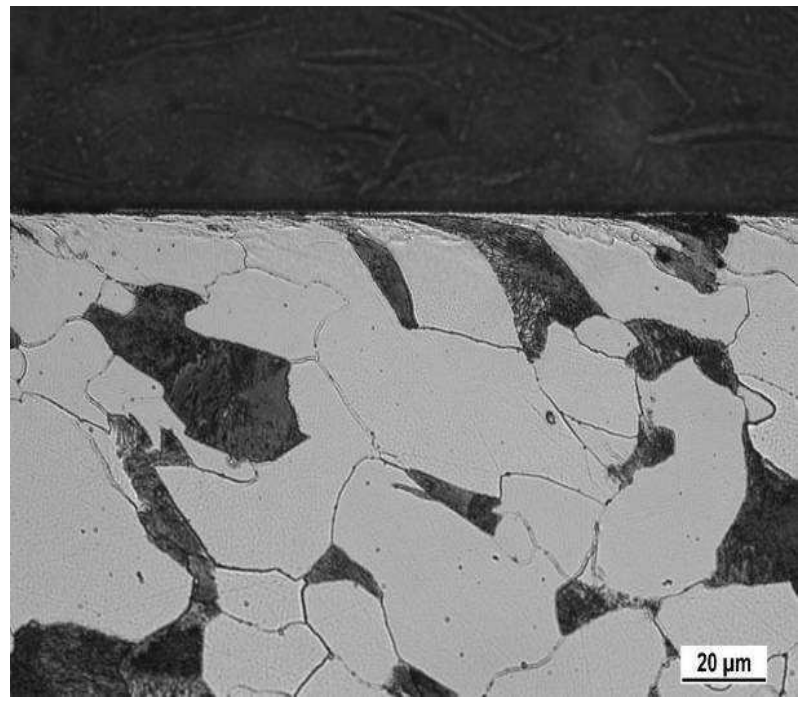

Fig. 3 Metallographic observation of turned surface, VB $=0.47 \mathrm{~mm}$

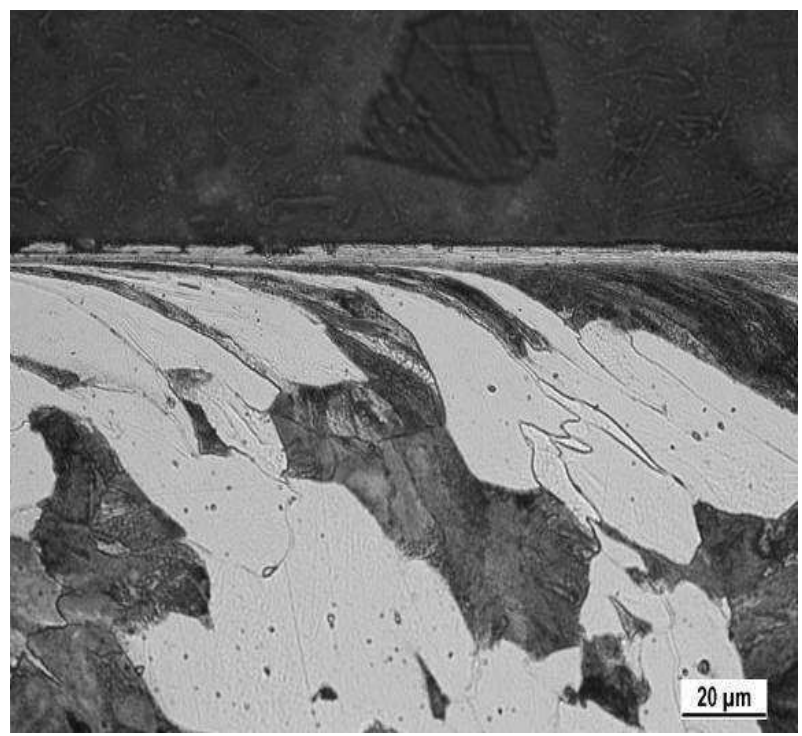

Fig. 4 Metallographic observation of turned surface, VB $=0.6 \mathrm{~mm}$

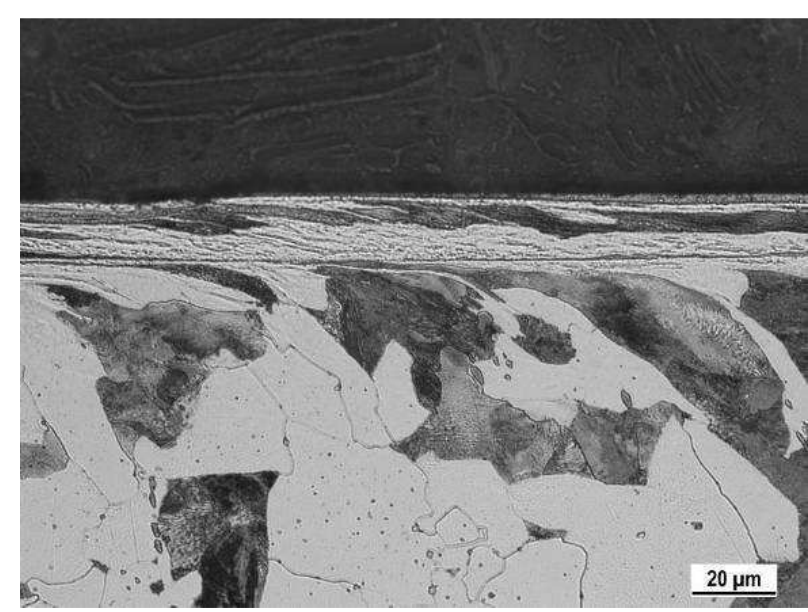

Fig. 5 Metallographic observation of turned surface, VB $=0.95 \mathrm{~mm}$

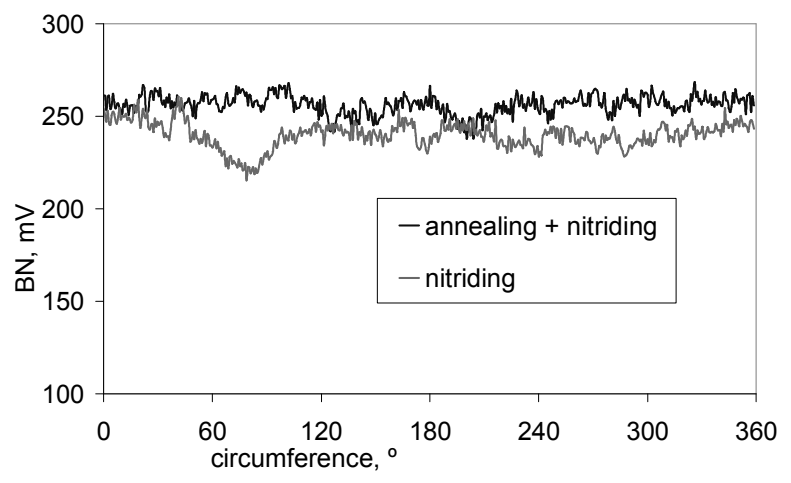

Fig. 6 Dynamic $B N$ records for surfaces turned by insert of $V B=0.05 \mathrm{~mm}$

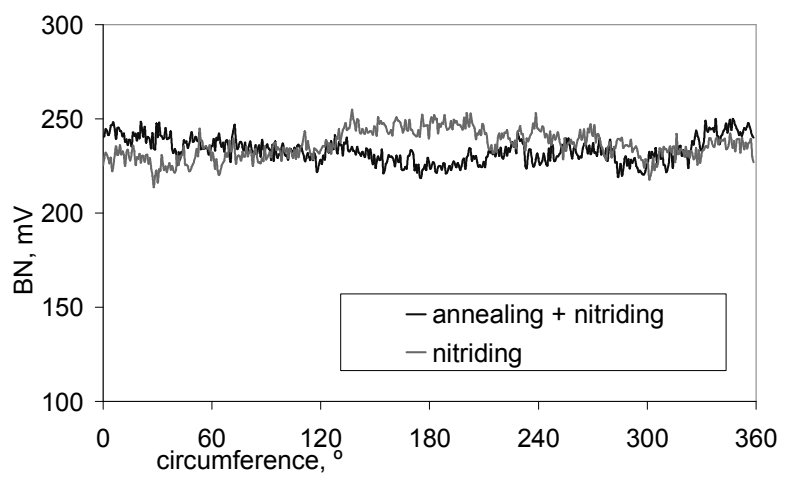

Fig. 7 Dynamic $B N$ records for surfaces turned by insert of $V B=0.25 \mathrm{~mm}$

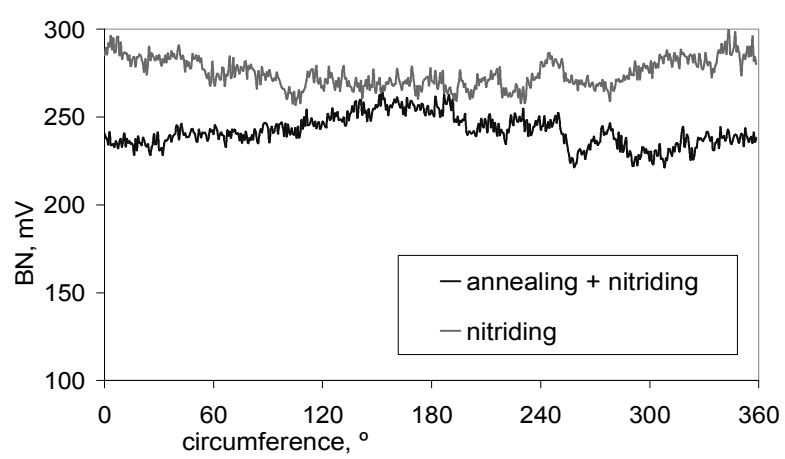

Fig. 8 Dynamic $B N$ records for surfaces turned by insert of $V B=0.47 \mathrm{~mm}$ 


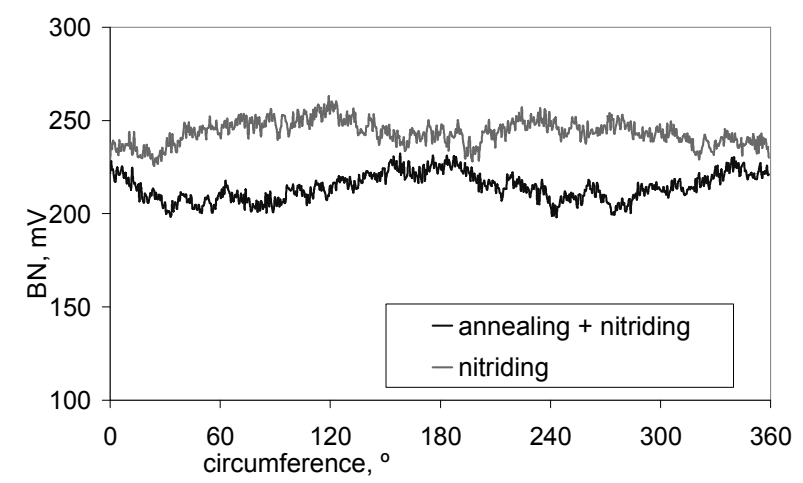

Fig. 9 Dynamic $B N$ records for surfaces turned by insert of $V B=0.60 \mathrm{~mm}$

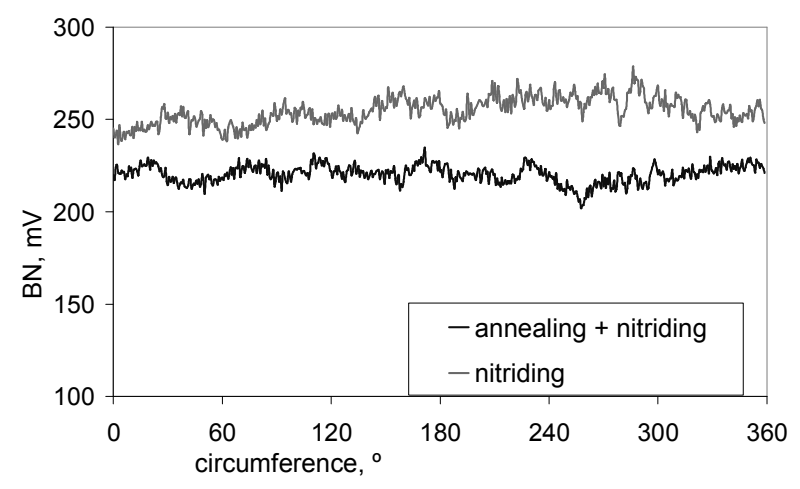

Fig. 10 Dynamic BN records for surfaces turned by insert of $V B=0.95 \mathrm{~mm}$

Metallographic observation of nitrided samples illustrates Figs. 11, 12. The micro graphs show that the thickness of compound layer is nearly twice higher for only nitrided samples that those undergoing annealing and the consecutive nitriding process. The thickness of compound layers for $V B=0.05$ and $0.25 \mathrm{~mm}$ is nearly same and does not depend on regime of heat treatment (combination of annealing and/or nitriding). On the other hand, the differences between nitrided and annealed + nitrided samples become more visible for higher $V B$. It is worth to mention that compound layer itself does not produces BN emission only creates the gap between the sensor and the underlying ferromagnetic diffusion layer.

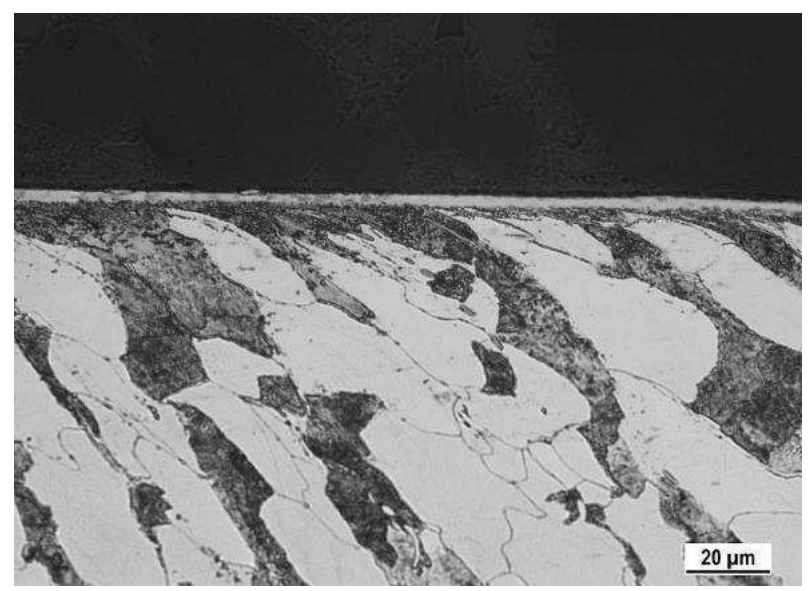

Fig. 11 Metallographic observation of the annealed and nitrided surface, $V B=0.60 \mathrm{~mm}$, nital $3 \%$

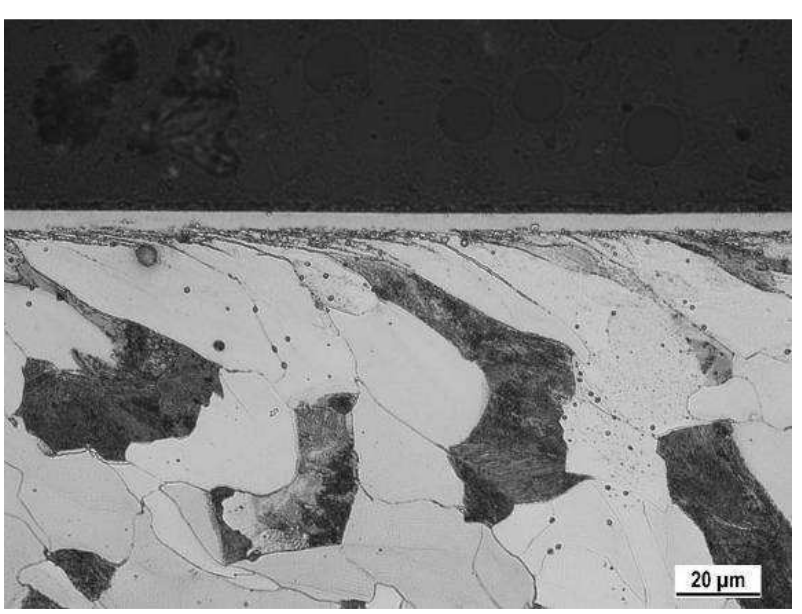

Fig. 12 Metallographic observation of nitrided surface, $V B=0.60 \mathrm{~mm}$, nital $3 \%$

Being so, the differences among the dynamic $\mathrm{BN}$ values considering the different $V B$ and regimes of heat treatment should be associated with the diffusion matrix as the region below the compound layer. Its properties can be easily expressed in term of micro hardness since the hardness of a body after nitriding is driven by the density of the nitrides. Some chosen microhardness profiles illustrates Fig. 13 as they were measured in the real industrial conditions of company Rubig SK, k. s. Internal standards prescribe to measure hardness HV0.5 (500 g loading for 10 seconds). Such measurement enables to indicate first intent at the distance approx. $0.05 \mathrm{~mm}$ beneath the free surface. The profiles illustrated in Fig. 13 depict no remarkable differences among the different samples neither considering the different $V B$ nor the different heat treatment regimes. Metallographic observations (thickness of compound layers) as well as the microhardness profiles are controversial with respect to $\mathrm{BN}$ values as those shown in Figs. $6 \div 10$ since the especially higher hardness of the matrix should correspond with lower $\mathrm{BN}$ values [13].

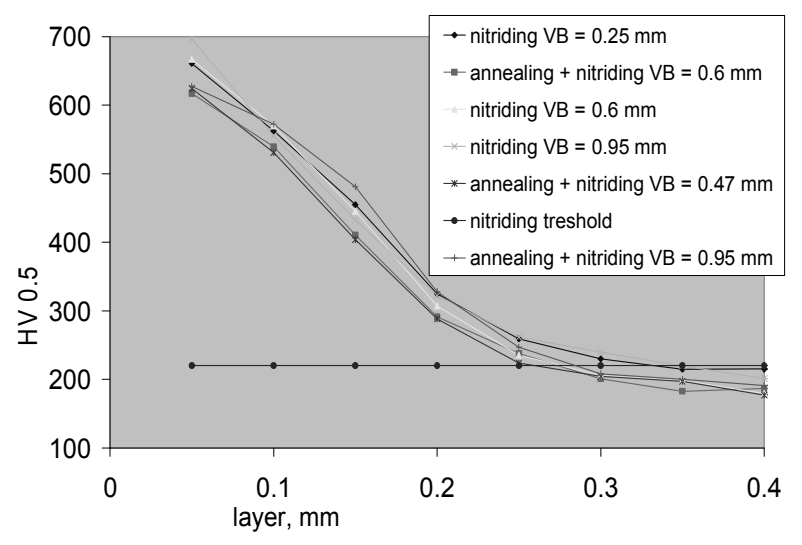

Fig. 13 Microhardness profiles

As it was mentioned above, compound layer does not produces $\mathrm{BN}$ emission only creates the gap between the sensor and the underlying ferromagnetic diffusion layer. $\mathrm{BN}$ sensitive depth is approx. $40 \mu \mathrm{m}$. For this reason, measurement of microhardness measurement in the region $50 \mu \mathrm{m}$ beneath the free surface and deeper is outside 
the $\mathrm{BN}$ sensitive region. Moreover, the transformations of the near surface region initiated by the turning process occur in the near surface region of thickness from a few micrometers up to $30 \mu \mathrm{m}$ (see Figs. $1 \div 5$ ). Being so, the additional laboratory measurement in the laboratory conditions was carried out to measure hardness in the thin near surface region affected turning process with load $25 \mathrm{~g}$ for 10 seconds. Repetitive measurements at the distance from 20 to $30 \mu \mathrm{m}$ on the samples after nitriding (respective annealing and the consecutive nitriding) indicate the different hardness of the matrix as a function of $V B$ as well as the different heat treatment regimes. However the microhardness profile is complicated since the hardness of ferrite phase (after nitriding) is about $100 \mathrm{HV}$ higher than pearlite phase.

\section{Conclusions}

It is necessary to notice that also other $\mathrm{BN}$ parameters (except conventional rms value) could be potentially extracted from the raw BN signal and used for non destructive monitoring of surfaces such as BN envelopes, position of envelope maximum, number of $\mathrm{BN}$ pulses, ect. This is only the pilot study focused on monitoring surfaces after plasma nitriding and further analysis will be carried out in the near future. However, this study indicates that $\mathrm{BN}$ emission is a promising technique for monitoring of components after nitriding process.

\section{Acknowledgement}

This study was supported by VEGA project $n$. 1/0121/17, $K E G A$ project n. 008ŽU-4/2018 and APVV project “Danube strategy 2016-0013”.

\section{References}

[1] TOTTEN, G.E. (2006). Steel Heat Treatment. second ed., Taylor\&Francis Group, Oregon.

[2] MIRJANI, M., MAZROOEI, J., KARIMZADEH, N., ASHRAFIZADEH, F. (2012). Investigation of the effects of time and temperature of oxidation on corrosion behavior of plasma nitrided AISI 4140 steel. Surf. \& Coat. Technol. 205, pp. 4389-4393.

[3] ATAPOUR, M., ASHRAFIZADEH, F. (2012). Cyclic oxidation of plasma nitrided valve steels. Phys. Procedia 32, pp. 853-860.
[4] NADDAF, M. et all. (2002). Nitridation of steel using a microwave ECR plasma. Vacuum 64, pp. 163-168.

[5] MAROT, L., PICHON, L., DROUET, M., STRABONI, A. (2000). Improved nitrogen transport in $\mathrm{Fe}-\mathrm{C}$ alloys during $\mathrm{NH}_{3}$ plasma nitridation. Mater. Letters 44, pp. 35-38.

[6] FLORI, M. et all. (2008). EPMA and microstructural analysis of a defective industrial plasma-nitrided steel. Surf. \& Coat. Technol. 202, pp. 58875894.

[7] MOORTHY, V. et all. (2001). Evaluation of heat treatment and deformation induced changes in material properties in gear steels using magnetic Barkhausen noise analysis, ICBM 03, Tampere.

[8] RANJAN, R. et all. (1987). Magnetic properties of decarburized steels: An investigation of the effects of grain size and carbon content. IEEE Trans. Magn. 23 (3), pp. 1869-1876.

[9] ČÍŽEK, J. et all. (2014). Modification of steel surfaces induced by turning: non-destructive characterization using Barkhausen noise and positron annihilation. J. Phys. D, Appl. Phys. 47, pp. 1-17.

[10] NESLUŠAN, M. et all. (2017). Monitoring of grinding burn via Barkhausen noise emission in case-hardened steel in large-bearing production. $J$. Mater. Proc. Technol. 240, pp. 104-117.

[11] MIČÚCH, M. et all. (2014). Micro magnetic study of cutting conditions and grinding wheel wear influence on surface integrity. Manufacturing Technology Vol. 14, pp. 66-71.

[12] NESLUŠAN, M. et. all (2016). Barkhausen noise emission in case-hardened bearing steel, Manufacturing technology Vol. 16, pp. 214-220.

[13] FARDA, R. (2017). Vplyv režimu tepelného a chemicko-tepelného spracovania na emisiu Barkhausenovho šumu. DDP, KOVT SjF ŽU 2017.

[14] SCHORNÍK, V. et. al (2017). Influence of ground end mill surface quality on cutting tool life, Manufacturing technology Vol. 17, pp. 952-957. 